\title{
A Perception Gap Model Based on the Dual Perspectives of Customer Value: A Conceptual Framework
}

\author{
Sun Zhongqun* \\ Business School, China University of Political Science and Law, No.27 Fu Xue Road, Changping \\ District, Beijing, China, 102249 \\ singersun325@hotmail.com
}

\begin{abstract}
Keywords: Dual perspectives of customer value; Perception gap; Gap model
\end{abstract}
Abstract. The purpose of the paper is to explore a perception gap model based on the dual perspectives of customer value. This is achieved through discussing on the five perception gaps of customer value between the company and its customers. Collectively, these gaps include: attribute gap, importance gap, performance gap, competitive gap and total gap. Then, we construct a priority matrix based on the degree of importance for customer value, as well as the size of the total gap from the customer's perspective.

\section{Introduction}

Satisfactory customer value serves as a premise for an assumed level of customer satisfaction and as a source of differentiation for competitive advantage ${ }^{[1]}$. However, due to the asymmetry of information between the supplier and the demander, there's usually a perception gap that tends to occur. This gap exists between "the value an enterprise wants to supply" and "the value a customer wants to have." In this way, it is common that an enterprise can underperform in terms of customer value management, and sometimes, they will pay high costs for this underperformance. Therefore, it is of significant theoretical importance and practical value to integrate the current theories and methods concerning the customer value gap. It is also important to propose an analytical framework and application process for achieving the systematic identification of the value perception gap between enterprises and the customers. By referring to Chinese and foreign research findings related to this field, this paper raises the idea of building a "gap model." This "gap model" is based on the dual perspectives of customer value. It divides the perception gap about customer value into the attribute gap, importance gap, performance gap, competitive gap and the total gap. It then builds a priority matrix based on the importance of customer value from customer's perspective and the size of the total gap. This is done in a bid to uncover any customer value gaps that must be promptly bridged by an enterprise. Doing so will allow them to concentrate limited resources on the critical areas that will help to contribute to increased customer value.

\section{Customer Value Gap Model}

A collection of service quality studies PZB (Parasuraman, Zeithaml and Berry, 1988) was the first to propose SERVQUAL model. ${ }^{[2]}$ This is a universal tool for evaluating overall service quality. It is based on service attributes, including reliability, guarantees, tangibility, accountability and empathy. It also measures any possible gaps that exist between customer expectation and their perceptions by means of a questionnaire survey. Ultimately, these gaps lead to the satisfaction/dissatisfaction of customers. With this as a starting point, we refer to studies by Curry(1999 ${ }^{[3]}$ and Luk \& Layton(2002) ${ }^{[4]}$ in order to reach the 7 gaps that can lead to customer dissatisfaction. These gaps are as follows: 1) the perception gap - which refers to the gap between customer' expectations and the management perceptions; 2) the standard gap - which means the gap between the management perception of customer expectations and the service specifications; 3) the performance gap - which is the gap between service specifications and service delivery; 4) the communication gap - which is the gap between service delivery and external communication; 5) the perception gap - which refers to the gap 
between customer expectations and their perceptions of the service delivered; 6) the discrepancy between customer expectations and employees' perceptions; and 7) the discrepancy between employee's perceptions and management perceptions (Gap 7 is the function of the other 6 gaps).

Today, SERVQUAL model is deemed an authoritative tool for service quality evaluation. It features three main functions: first, the SERVQUAL scale should be filled-in by external customers and internal staff. This should be done in order to identify the gap between customer expectations and enterprise perceptions after comparison. Second, by comparing customer expectations and perceptions at different time points, measures for improvement can be made on the basis of a cause analysis. Finally, through comparative studies into the services provided by a company and its rivals, the strengths and weaknesses of the company can be identified in terms of the different dimensions of service quality.

A team of customer value studies JRO (Jeanke, Ron and Onno, 2001) has described all of the possible gaps between the supplier and the customer at different steps in the process of developing, producing and delivering products ${ }^{[5]}$. For the supplier, they will typically come to "the value they want to supply." This is based on their perceptions about customer demands and the strategic intent, resources and capacity of the enterprise. Limited by an enterprise's conditions and capacities, the products or services they develop may not always meet market demands. This leads to a "design gap" between the "design value" (assumed by the actually developed product) and "the value they want to supply". For the customer, they would always like to acquire "the value they want to have" from their own perspective. Meanwhile, the products and services provided by the external market cannot always meet up with such a value. This leads to a "compromise gap." For both parties of supply and demand, and due to any asymmetry in the information about the customer demands between them, or due to any inappropriate intervention in an enterprise's will in marketing research, an "information gap" will arise. This occurs between "the value they want to supply" and "the value they want to have." Furthermore, the subjectivity and one-sidedness a customer's value perception can give rise to a "perception gap." This occurs between "the expected value" and "the designed value". In the course of consumption, any inconformity between the "acquired value" and the "expected value" of products and services for customers is said to make up the "satisfaction gap".

Based on the theory of customer delivered value, Hou \& Tang (2007) suggested studying the gap between the enterprise and the customer in terms of the customer's value perception from dual perspectives. ${ }^{[6]}$ They believed the gap in customer value consists of a vertical gap and a horizontal gap. Here, the vertical gap refers to the gap in the perceptions within an enterprise. Examples here include gaps in product design, performance gaps, constitution gaps and satisfaction gaps. A gap in product design means that an enterprise's error in identifying customer interests leads to an inconformity in products and services with market demands. A performance gap means that an enterprise, limited by its resources and capacities, cannot develop ideal products and services for customers. A constitution gap means that an enterprise, limited by technological, social and other factors, cannot supply products or services that fully meet customer demands. Finally, a satisfaction gap refers to the gap between the products or services perceived by customers and the products or services that they expect. A horizontal gap refers to the gap between customer value from the perspective of the enterprise and customer value from the perspective of the customer. This generally includes the information gap, communication gap and the gap in perceived value. Here, the information gap refers to the gap between the enterprises' products and the customers' demands that are caused by asymmetry in information between enterprises and customers or the lack of neutrality during an enterprises' survey of customers' demands. The communication gap refers to the gap caused by ineffective communication between enterprises and customers. The gap of perceived value means the gap that arises due to different evaluations of customers and enterprises in terms of products and services.

The customer value gap models mentioned above can all reveal value gaps between an enterprise and the customer from different respects. This can help enterprises discover and measure gaps as they exist at different layers in order to allow them to take pertinent measures to help correct them. However, developments in marketing practices have shown the limitations of current value gap models. The first problem involves the relationship between the dual perspectives of enterprise and 
customer concerning customer value. Here, current models for the customer value gap are mostly focused only on customer value. This is the only information used to study how to bridge the gaps. This means that many enterprises pay high prices to help raise customer satisfaction and perceived value by the customer. However, the dual customer value perspectives feature a unity of opposites; namely, there is a relationship of mutual dependence and restriction. There can also be favorable interactions and balanced development between the customer value acquired by an enterprise and the customer value it actually provides for customers ${ }^{[7]}$. The second problem involves the dual perspectives concerning the customer value gap. Current customer value gap models define that the perception gap between "the value an enterprise wants to supply" and "the value a customer wants to have" as the primary gap. In this way, they are unable to probe the perception gap from the respect of attributes, importance, performance and competition. The final problem involves the relationship between the customer value gap and an enterprise's management of customer value. Here, findings generally propose ways to help bridge gaps from the perspectives of value chain development and the service management process. They do not deal with ways of optimizing the customer value management ability or build core competitiveness at the level of corporate strategic management.

\section{A Gap Model Based on the Dual Perspectives of Customer Value: A Basic Framework}

The process of customer value creation for an enterprise is, in fact, a process of spotting, defining, delivering and communicating customer value ${ }^{[8]}$. On the other hand, the process of value perception for a customer is a process of value demand, expectation, acquisition and perception. Due to the asymmetry of information that exists between the supplier and the demander, there is typically a perception gap. This perception gap exists between customer value from an enterprise's perspective and the one from a customer's perspective. To make an all-round analysis of all possible perception gaps that exist between "the process of value creation of an enterprise" and "the process of value perception of a customer", this paper presents a perception gap model based on dual perspectives of customer value (refer to Picture 1). This model features a basic flow. Here, we define the different elements of customer value and measure the perception gaps of customer value from the dual perspectives of the enterprise and customer. We also create a priority matrix according to the importance of customer value elements and the size of the total gap. This process allows us to promote customer value management more pertinently.

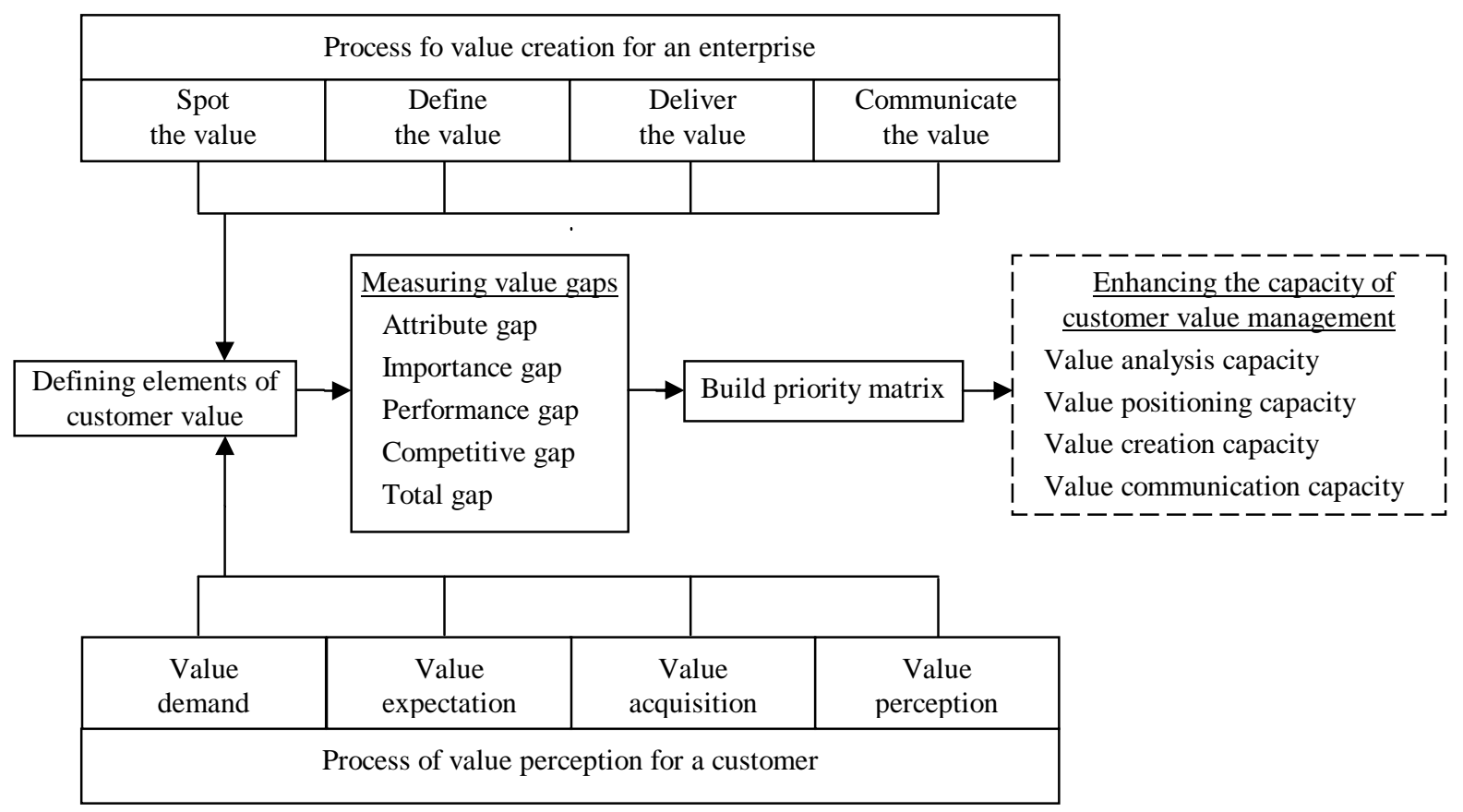

Figure1 A Gap Model on Dual Perspectives of Customer Value 
Defining elements of customer value. Elements of customer value are the main sources of customer perceived value. They play an important role in customer purchasing behavior. Therefore, the first step in building a gap model based on the dual perspectives of customer value is to analyze the value perception process for a customer. It is also necessary to systematically identify the inherent driving factors behind customer purchasing behavior - namely, the elements of customer value.

Before determining all of the elements of value, it should be noted that it would be impractical to study a portfolio of elements that is universally applicable. This is due to the obvious differences that exist between different industries. Therefore, the paper suggests that no distinction in dimensions and elements of customer value should be made in advance. Rather, the identification of customer value elements should be made through research procedures based on the factor structures found in extant models. They should also be made through the specialties in the products or services provided by each particular enterprise. These specific methods are: 1) Focus group studies - these studies select representative customers to make up a focus group, and explore information about customer expectations through group discussions. They also list customer value elements as alternatives, and then remove redundant items that are too low in their mean value of expectation after preliminary testing. At this point, they extract different dimensions and indicators of value through exploratory factor analysis. Finally, they conduct validity and reliability tests of indicators for an exploratory factor analysis. This is done in order to discover the elements of customer expected value (and their hierarchical structure). 2) Analysis of the customer value chain - these help to uncover the customer value chain level by level. They do so from the perspective of customer and conduct an in-depth and systematic analysis about perceived benefits and sacrifices from the customer at different steps in the value chain. These steps include: pre-sale, during-sale, use and consumption. They then systematically reveal the fundamental elements of value perception and evaluation for the customer. The specific methods may involve revealing the customer value chain level by level in order to obtain value elements that are worthy of consideration. They also involve establishing a preliminary questionnaire and conducting preliminary targeted research. At this point, appropriate selections and adjustments are made according to the research results. This process reveals the more meaningful final value elements.

Measuring customer value gaps. Due to the asymmetry in information between the supplier and the demander, it can be quite hard for an enterprise to grasp the overall customer demands and the driving factors for value. Furthermore, customers usually find it hard to perceive and evaluate the value actually being supplied by an enterprise. This is due to incomplete consumption rationality. Therefore, in order to make an all-round analysis of the gap in customer value perception between the enterprise and the customer, it becomes necessary to conduct systematic measurement and analysis. This must be done according to the attribute gap, importance gap, performance gap, and competitive gap (see Table 1). The measurement in this part consists of 4 steps: 1) to deliver questionnaires to related personnel in enterprises and customers. This is done in order to determine the key value elements, the weights of these key value elements and any ideas about rival performances in key value elements from the perspectives of both the enterprise and the customer; 2) to get the standard value through the entropy weight method according to the data collected via a questionnaire scale; 3) to subtract the standard value for the enterprise's perspective from the standard value for the customer's perspective. This is done in order to obtain the importance gap, execution perception gap and the competitive gap. Whenever the gap value is positive, it means the level perceived by the customer is higher than that perceived by the enterprise; 4) to total the squared value of each gap based on certain weights, and then extract the square root in order to obtain the total gap value. 
Table 1. Gap Analysis

\begin{tabular}{|c|c|c|c|l|l|}
\hline $\begin{array}{c}\text { Customer } \\
\text { value } \\
\text { elements }\end{array}$ & $\begin{array}{c}\text { Attribute } \\
\text { gap }\end{array}$ & $\begin{array}{c}\text { Importance } \\
\text { gap }\end{array}$ & $\begin{array}{c}\text { Delivery } \\
\text { gap }\end{array}$ & $\begin{array}{c}\text { Competitive } \\
\text { gap }\end{array}$ & $\begin{array}{c}\text { Total } \\
\text { gap }\end{array}$ \\
\hline Element 1 & & & & & \\
\hline Element2 & & & & & \\
\hline Element3 & & & & & \\
\hline Element... & & & & & \\
\hline Element $\mathrm{N}$ & & & & & \\
\hline
\end{tabular}

The attribute gap. Different customer value elements can play different driving forces in the overall structure of customer value. Furthermore, the purchasing behavior of the customer is typically controlled by key driving elements. Therefore, an enterprise must first define the constitution of the key driving elements for customer value. Then, it must measure the difference between the enterprise and target customers in terms of their perception of key driving elements. For instance, an enterprise may believe some indicator to be the key driving element that will impact customer purchasing behavior; however, from the perspective of the customer, they may not believe the same thing. This is what is known as the attribute gap. By studying the attribute gap, key elements of customer value can be determined. On the other hand, the enterprise can also learn about the difference between their perceptions and the perceptions of the customer in terms of the ideas about customer value constitution according to the gap.

The importance gap.The importance gap refers to the difference between the enterprise and target customers in the way they perceiving the relative importance of perceived value elements. For instance, an enterprise may believe that some indicator has a relative importance of 0.3 ; however, the customer may attach only a 0.1 ranking to it. This is what is called the importance gap. By studying the importance gap, the enterprise can identify the weights of customer value elements in terms of the customer's value perception. This can help to ensure that the orientation of the products or services provided by an enterprise meet up with the demand priorities of the customer.

The performance gap. The performance gap refers to the gap between the value that an enterprise believes it renders to the customer and the value that is actually perceived by the customer. The former is the subjective perception of an enterprise in terms of the value it creates and delivers to the customer. The latter is the judgment value that the customer places on the value of the products and services being supplied. For instance, while targeting indicator $\mathrm{C}$ in the elements of customer value, the enterprise believes that the value it renders to the customer can be graded at 9 points; however, the customer perceives this value as only being worth 7 points. By analyzing the performance gap, the enterprise can get a better picture of the gap between the value it actually delivers to the customer and the demand priorities of the customer. In doing so, the enterprise can supply more effective products and services to the customer.

The competitive gap. The competitive gap refers to the difference between the enterprise and the customer in terms of their perception of the value elements for products or services provided by a rival. For instance, regarding indicator $\mathrm{D}$ in the customer value elements, the enterprise believes the rival can reach 7 points in this indicator. Meanwhile, in this case, the customer thinks the rival can achieve 9 points. By studying competitive gap, an enterprise can define its own strengths and weaknesses, as well as those of the rival, in terms of the "net earnings" in different dimensions of customer value. In this way, an enterprise can become more successful by improving its marketing program.

Total gap. The total gap refers to an aggregated analysis of the importance gap, performance gap and competitive gap. This is done in accordance with certain weights. The purpose of studying the total 
gap is to define the most urgent gap that an enterprise must deal with first. This helps the enterprise to lay down a foundation for building a priority model.

Building the importance-gap combined matrix. After the total gap is obtained, this paper will build a priority matrix according to the importance degrees for customer value elements. The size of the total gap as shown in Picture 2.

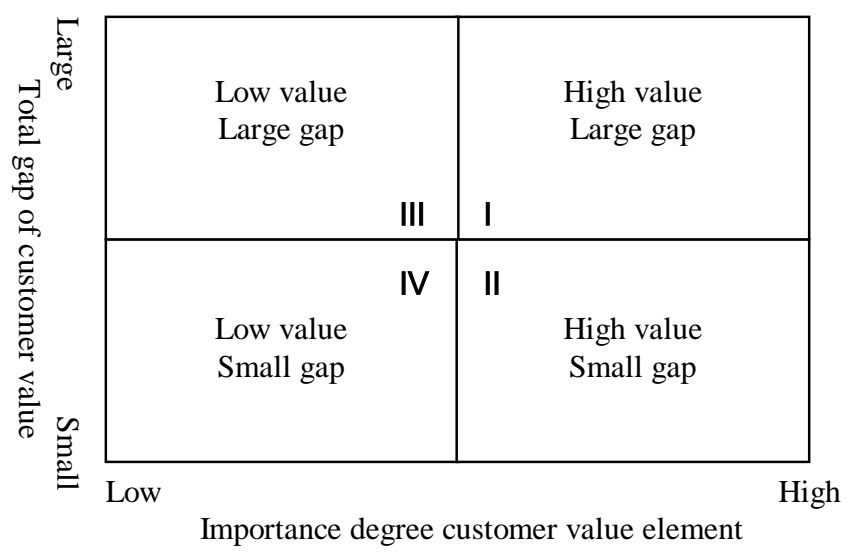

Figure2 Importance-Gap Combined Matrix

Quadrant I: The customer believes these value elements are of relatively high importance, and the gap between the dual perspectives of customer value is relatively large. By bridging the gaps at the key elements of customer value, an enterprise can raise overall customer value. This allows the enterprise to achieve a high-performance competitive advantage. Therefore, these are Grade-A gaps that require immediate improvement.

Quadrant II: The customer believes these value elements are of relatively high importance, and the gap between the dual perspectives of customer value is relatively small. Here, the enterprise has little room for improvement in key elements of customer value. This indicates that there is a relatively low marginal benefit of customer value and competitive advantage. Therefore, these are Grade-B gaps that must be improved.

Quadrant III: The customer believes these value elements are of relatively low importance, but the gap between the dual perspectives of customer value is relatively large. Here, the enterprise has great room for improvement in the non-key elements of customer value. Therefore, the enterprise may consider taking measures for bridging these gaps that are within its power. These are Grade-C gaps to be improved.

Quadrant IV: The customer believes these value elements are of little importance, and the gap between the dual perspectives of customer value is relatively small. An enterprise's improvement for such gaps of low value and low performance will not lead to satisfactory customer value or an enhancement of competitive advantage. Therefore, these are Grade-D gaps for improvement.

Enhancing the capacity of customer value management. The gap model based on the dual perspectives of customer value and the "importance-gap combined matrix" have revealed the direction for training the ability of customer value management. They have also provided a path for enterprises to win a competitive advantage. When viewing an enterprise's capacity in customer value management from the dual perspectives provided by customer value gaps, the capacity structure of an enterprise must consists of 4 main parts. These four parts are: the capacity of value analysis, the capacity of value orientation, the capacity of value creation and the capacity of value communication. The capacity of value analysis refers to the capacity with which an enterprise identifies the key value driving elements of the target customer. It also analyzes and compares the value performances of the enterprise and its rivals and substitute suppliers and forecasts the dynamics associated with customer value structure. Finally, it understands the gap between the value supplied by the enterprise and the customer's expected value. The capacity of value orientation means the capacity with which an enterprise 
understands the actual and potential value selection standards of the target customer. It exactly defines the values they supply to the target customer and value proposition by considering its own resources and capacity advantage. The capacity of value delivery refers to the capacity with which an enterprise adopts an appropriate management system and operation process under the guidance of customer value proposition. It also refers to the way an enterprise develops and supplies marketable products or services in a bid to achieve the customer's value expectation. The capacity of value communication is the capacity with which an enterprise effectively conducts dual-way communication with target customers. It involves the ability to precisely convey the enterprise's value proposition and the value guarantee of its products to the target customers in a timely manner. This will allow them to understand and accept the value the enterprise creates for them, thus narrowing the overall perception gap of customer value.

\section{Conclusions}

The reason for studying customer value gaps is to help reveal the differences between the enterprise and the customer in terms of value perception gaps. It also helps to determine the value compositon and expectations of the customer and compare the enterprise's value delivery with the customer's value expectations. Performing this type of analysis also helps to define the difference between the enterprise and its rival in terms of customer value. This can help an enterprise to concentrate its limited resources on key areas that will provide the largest contribution to improving overall customer value. From a brand-new perspective, this paper proposes a gap model based on the dual perspectives of customer value. This has been used to study the attribute gap, importance gap, performance gap, competitive gap and the total gap between the enterprise and the customer in terms of the perception of customer value. This paper then constructed a priority matrix according to the importance degrees of customer value from the perspective of the customer and the size of the total gap. This new model will facilitate an enterprise's all-round analysis concerning the perception gap of customer value. It will also provide information about the orientation of customer value and pertinent enhancement of the capacity of customer value management. In the future, the operability and research potential of this model must be further stressed and validated through empirical analysis.

\section{References}

${ }^{[1]}$ R.B. Woodruff, Customer Value: The next source for competitive advantage, J. Journal of the Academy of Marketing Science, 25 (1997) 139-153.

${ }^{[2]}$ A. Parasuraman, V.A. Zeithaml, L.L. Berry, SERVQUAL: A multiple-item scale for measuring consumer perceptions of service quality, J. Journal of Retailing, 64(1) (1988) 12-40.

${ }^{[3]}$ A. Curry, Innovation in public service management, J. Managing Service Quality, 9 (1999) 180-190.

${ }^{[4]}$ Sh.T.K. Luk, R. Layton, Perception gaps in customer expectations: managers versus service providers and customers, J. The Service Industries Journal, 22(2) (2002) 109-128.

${ }^{[5]}$ J. W. van der Haar, R. G. M. Kemp, Onno Omta, Creating value that cannot be copied, J. Industrial Marketing Management, 30 (2001) 627-636.

${ }^{[6]}$ Hou Lun, Tang Xiaowo, Gap model for dual customer values, J. Tsinghua Science \& Technology, 13 (2008) 395-399.

${ }^{[7]}$ Sun Zhongqun, Sun Xi, Customer segmentation based on dual perspectives of customer value. Lecture Notes in Electrical Engineering 217 (2013) 129-138.

${ }^{[8]}$ R. Kordupleski, J. Simpson, Mastering customer value management: the art and science of creating competitive advantage,.Pinnaflex Educational Resources Inc (2003). 